\title{
Categoria
}

Relato de Experiência

Titulo do Trabalho

\section{DEGRADAÇÃO SOCIOAMBIENTAL DO CÓRREGO DA ONÇA, TRÊS} LAGOAS/MS

\author{
Nome do Autor (a) Principal
}

\section{Jaqueline Santos França ${ }^{1}$}

Nome (s) do Coautor (a) (s)

Thiago Rocco dos Santos ${ }^{2}$; Weslen Manari Gomes ${ }^{3}$

Instituição ou Empresa

\section{Universidade Federal de Mato Grosso do Sul - Campus de Três Lagoas}

Instituição (s) de Fomento

E-mail de contato

jakeline_3ı@hotmail.com

RESUMO: O presente relato tem por finalidade apresentar a degradação socioambiental da bacia do córrego da Onça, que corta a cidade de Três Lagoas - MS. O trabalho buscou mostrar a trágica realidade que vive o córrego no que diz respeito à degradação ambiental, e também, mostrar como a questão ambiental pode influenciar diretamente a sociedade e na reprodução, e produção do espaço a qual ela está inserida. Buscou-se trabalhar com os principais conceitos geográficos como espaço, paisagem, lugar e território de maneira à interrelacionar aspectos físicos e sociais proporcionados pelas mudanças na cidade devido ao forte processo de industrialização. Essas mudanças puderam ser evidenciadas no trabalho de campo.

\footnotetext{
${ }_{1}^{1}$ Acadêmica do $5^{\circ}$ semestre do curso de Geografia licenciatura e bolsista PET, UFMS/CPTL.

${ }^{2}$ Acadêmico do $5^{\circ}$ semestre do curso de Geografia licenciatura e bolsista PET, UFMS/CPTL.

${ }^{3}$ Acadêmico do $5^{\circ}$ semestre do curso de Geografia licenciatura e bolsista permanência no laboratório de recursos hídricos, UFMS/CPTL.

Agradecimento em especial ao Prof. Dr. André Luiz Pinto, pela colaboração e revisão do trabalho.
} 
Palavras-Chave: degradação; sociedade; espaço.

\section{INTRODUÇÃO}

Ao longo dos anos muito se questionou o verdadeiro papel do geógrafo, visto que a Geografia durante algumas décadas passou por uma série de dificuldades que faziam com que a mesma fechasse os olhos para as situações que envolviam a problemática social como tema principal das discussões.

Contudo, com o amadurecimento do que chamamos hoje de Geografia crítica, pode-se perceber o geógrafo mais atento as principais problemáticas mundiais, e, muito mais conciso nas suas definições que envolvem a leitura e compreensão do que está acontecendo a todo momento no seu espaço vivido de cada dia, como dizia Santos: "O espaço é um misto, um híbrido, um composto de formas - conteúdo" (2009, p. 42).

Como foi dito o espaço é algo abrangente, uma verdadeira "mistura", onde cabe ao geógrafo a sua análise de como os fatos e os objetos se relacionam, formando e remodelando o espaço de forma contínua.

Ao se trabalhar a degradação ambiental, um dos principais assuntos da atualidade, nós vemos a força que o geógrafo pode exercer sobre detalhes que para outro simples pesquisador podem passar despercebidos. Detalhes esses que envolvem não somente a existência de uma erosão ou a falta de mata ciliar nas margens de determinado córrego, mas sim analisar tudo isso, que diga-se de passagem já é muito, mas além disso levantar apontamentos sobre a influência desses processos na sociedade.

Para tanto foi realizada uma saída de campo ao córrego da onça, principal problema ambiental da cidade de Três Lagoas/MS, e a partir disso evidenciou-se as contradições existentes no espaço geográfico, buscando uma análise crítica sobre os fatores que influenciam a reprodução e produção desigual daquele determinado espaço. 


\section{OBJETIVO GERAL}

Identificar a situação atual de degradação do córrego da Onça, relacionando-a com o forte processo de industrialização/urbanização da cidade.

\section{OBJETIVOS ESPECÍFICOS}

Demonstrar a precária qualidade de vida dos moradores que residem ao entorno ou nas proximidades do referido córrego. Também buscar uma análise crítica sobre a formação do espaço de desigualdades presente nos bairros próximos ao córrego.

\section{METODOLOGIA}

Como procedimento metodológico foram realizadas saídas de campo para eventual conhecimento empírico da realidade do córrego trabalhado e da sociedade que ali está presente. Também foram utilizadas imagens do software Google Earth® para localizar 0 objeto de estudo e demonstrar as modificações em todo o seu caminho.

Para o construto teórico-metodológico foram levantadas bibliografias pertinentes aos temas e conceitos trabalhados pautando-se em autores como: Christofoletti (2009), Haesbaert (2005) e Santos (1992; 2009).

\section{RESULTADOS}

O acelerado processo de industrialização tem transformado de forma contínua a cidade de Três Lagoas, onde se observa a falta de planejamento da prefeitura e dos demais órgãos públicos que não possuem a devida competência para aliar o contraditório desenvolvimento com os cuidados necessários ao meio ambiente e as devidas providências em qualidade de vida para a população. 


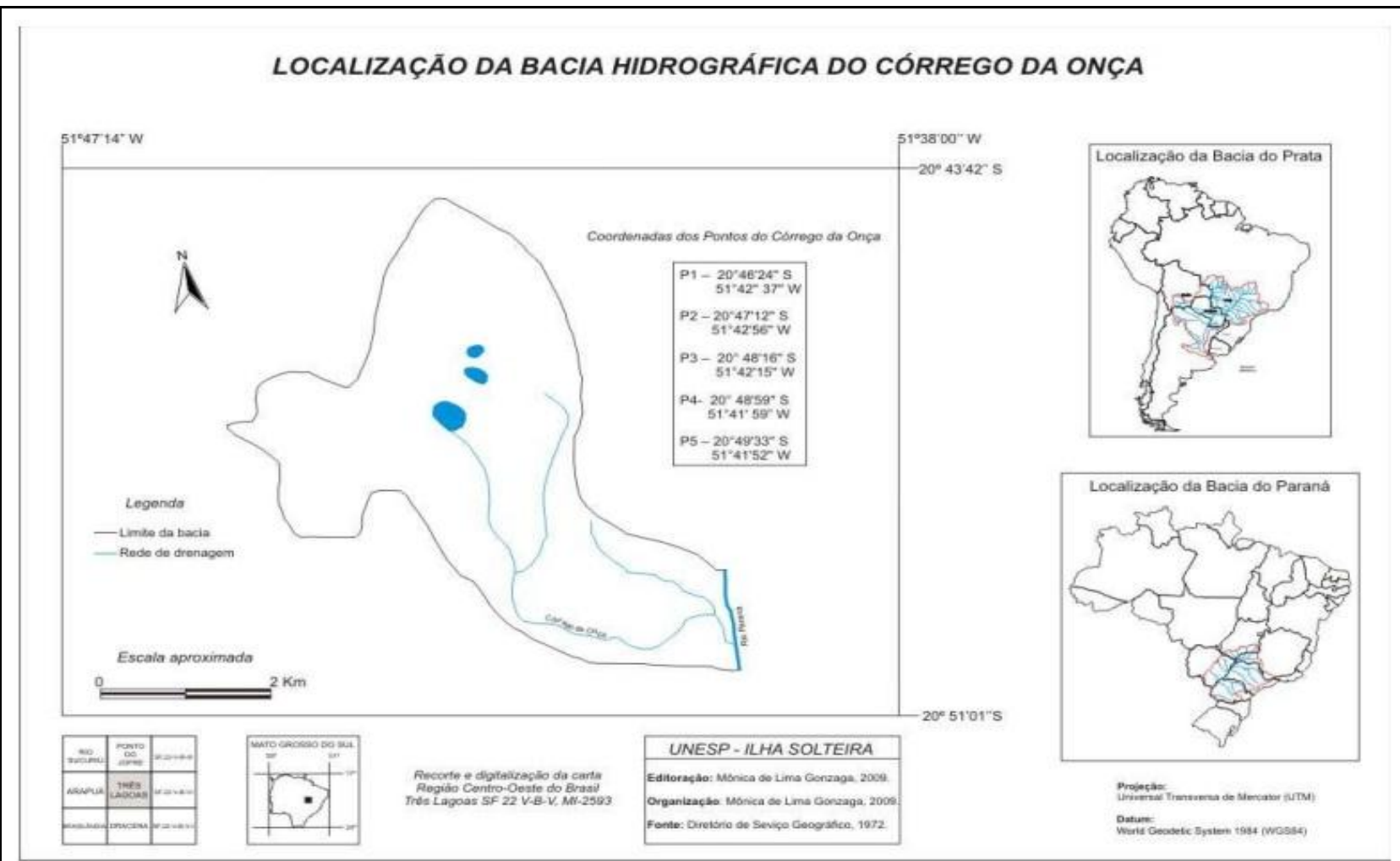

Figura1. Localização da Bacia Hidrográfica do Córrego da Onça - Três Lagoas - MS

Fonte: Unesp Ilha Solteira, 2009.

Ao chegarmos ao Córrego da Onça, na altura que divide os bairros Vila São João e Vila Zuque, observa-se o seu curso ter sido canalizado desde a lagoa maior até o bairro, notando-se a intensa degradação que o córrego sofre devido ao atual processo de urbanização de Três Lagoas.

No local podemos relacionar os conceitos geográficos trabalhados em sala, como por exemplo, o espaço demonstrando que o mesmo não é apenas um conjunto de simples objetos, ele é isso mais a sociedade que ali está presente distribuída nos bairros.

A noção de paisagem também é muito interessante, visto que o perceptível para nós é aquela sensação de "espanto" ao nos depararmos com tanto sujeira e condições precárias de vida dos moradores, visto que a paisagem pode ser considerada como resultado cumulativo dos tempos proveniente da interação dos objetos com a sociedade (SANTOS, 1992).

Podemos ver também como o território é configurado em função das relações entre sociedade e espaço, afirmando que: 
[...] o território, imerso em relações de dominação e/ou de apropriação sociedadeespaço, "desdobra-se ao longo de um continuum que vai da dominação políticaeconômica mais 'concreta' e 'funcional' à apropriação mais subjetiva e/ou 'culturalsimbólica'” (HAESBAERT, 2004, p. 95 - 96).

Sendo assim as pessoas que residem no bairro configuram territorialidades com 0 mesmo, uma vez que criam identidades com o lugar gostando ou não, já que mesmo com a aparência prejudicada pelo esquecimento, os referidos bairros são os lugares em que as casas dos moradores foram construídas, determinando o próprio território.

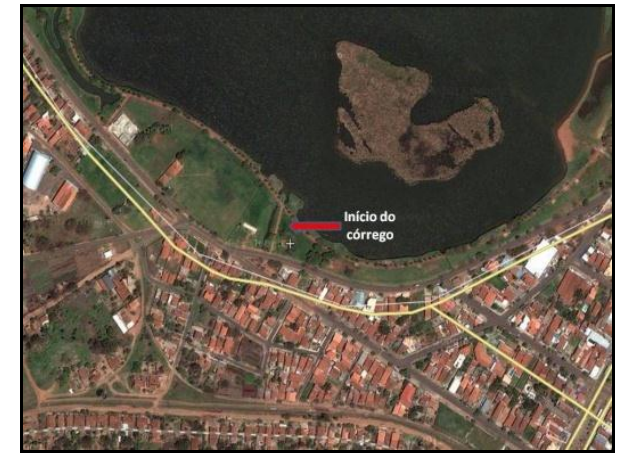

Figura 2: Início da canalização do córrego.

Fonte: Wikimapia, 2011.

Editoração: GOMES, W.M., 2011.

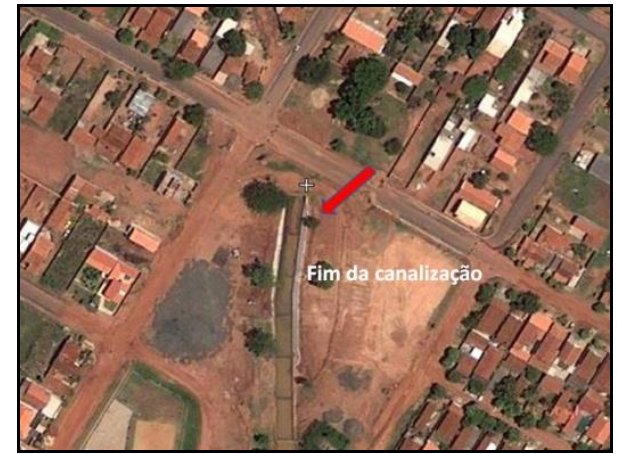

Figura 3: Término da canalização.

Fonte: Wikimapia, 2011.

Editoração: GOMES, W.M., 2011.

Vemos também o descaso não apenas com o meio ambiente, mas com a população que reside nas proximidades. O problema envolve esgoto a céu aberto, mau cheiro, lixo por toda margem do córrego, proporcionando assim baixíssima qualidade de vida para os moradores.

Além disso, ironicamente foi construída uma escola de educação infantil praticamente ao lado do córrego, onde a área que seria para lazer das crianças, 0 chamado "pátio" tem uma vista totalmente desmanchada pela sujeira devido ao descaso do poder público (Figura 5).

Contudo, ainda evidencia-se a grande falta de mata ciliar, e quando ela existe é deficiente não suprindo assim as necessidades do córrego. São vistos imensos terrenos com muito pasto, crianças a todo o momento passando por dentro do córrego sofrendo o grande risco de contaminação por contato direto com dejetos, e um serviço de engenharia 
falho da prefeitura municipal, onde por falta de vegetação as margens, que por sua vez tem a função de fixar o solo, as margens podem desmoronar com uma simples chuva.

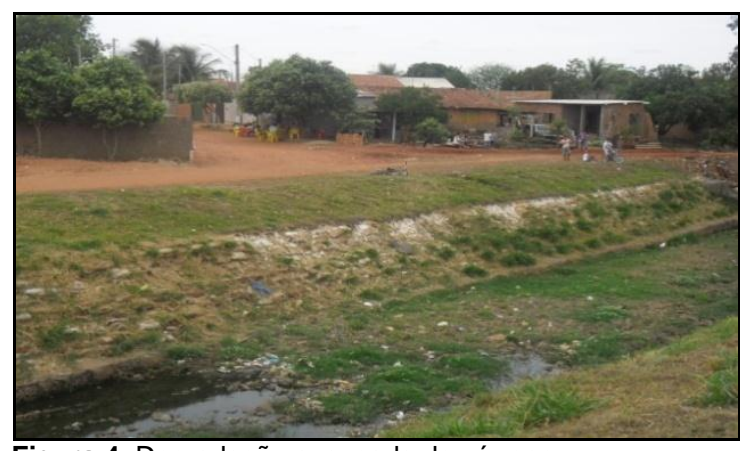

Figura 4: Degradação avançada do córrego.

Fonte: SANTOS, J.F., 2011.

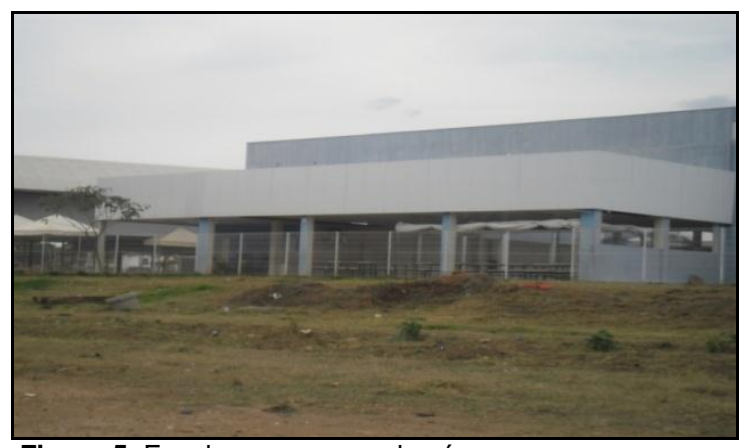

Figura 5: Escola as margens do córrego. Fonte: SANTOS, J.F., 2011.

É importante ressaltar o fato de que no trajeto que percorremos não encontramos se quer um aviso, placa que seja indicando necessidade de ter cuidado com o local, até porque é uma região íngreme com declividade brusca e crianças podem chegar a cair e se machucarem. Sendo assim, mais do que avisos seria necessário colocar-se proteção ao redor da área.

Adentramos assim, a mais um conceito geográfico, o de região, que podemos entender como um subespaço do espaço total, uma porção do espaço visto como totalidade (SANTOS, 1992).

Um pouco mais adiante encontramos um local "mais privilegiado", no sentido de que existe uma pequena faixa de mata ciliar, tendo em vista que estamos falando de um córrego que como tal necessita de uma determinada porção de mata ciliar, que por sua vez não é devidamente respeitada.

Notar-se-á também a presença de lixo, não só no interior do córrego, mas também nos barrancos que são relativamente altos, como por exemplo, sacolas, copos plásticos, latas de alumínio, que demonstram onde o nível da água pode chegar no período chuvoso.

Prosseguimos e notamos que na vizinhança parecem ser comuns os casos em que as pessoas costumam utilizar os terrenos baldios como locais para se jogar lixo, o que nos remete a pensar na falta de conscientização das pessoas (nem todas evidentemente) do local, as quais não tiveram uma adequada educação voltada para questões de saúde e meio ambiente. 


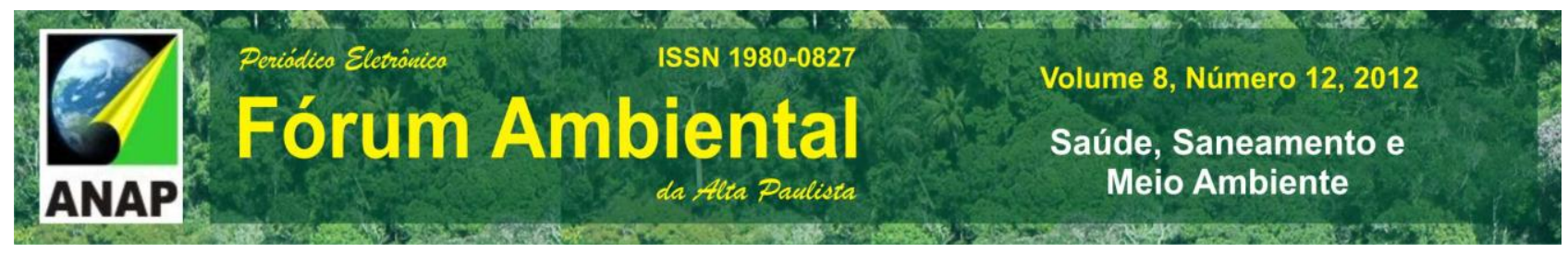

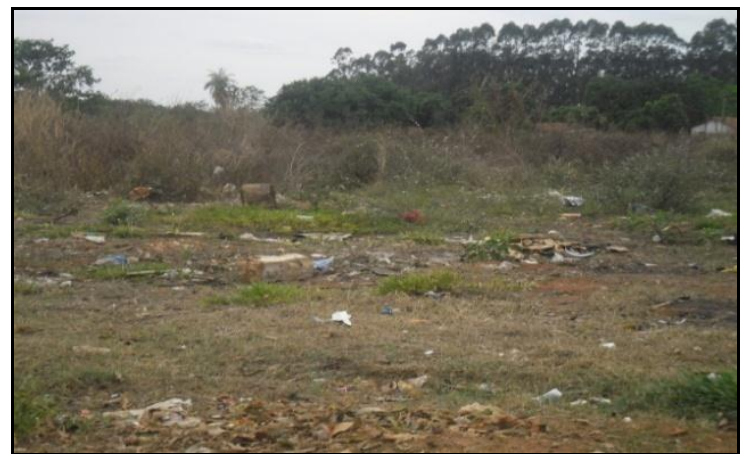

Figura 6: Lixo nos arredores do córrego e do bairro. Fonte: SANTOS, J.S., 2011.

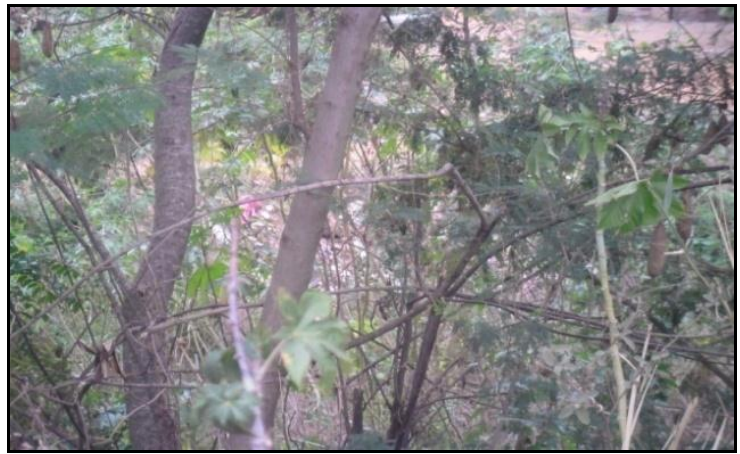

Figura 7: Alguns resquícios de mata. Fonte: SANTOS, J.F., 2011.

Já nas proximidades da estação de tratamento de esgoto nos deparamos com uma situação complicada, já que como foi dito antes, há a necessidade de uma mata ciliar para o córrego, no entanto o que encontramos foi uma região de pastagem, que por sua vez havia sido queimada fragilizando a pouca vegetação de médio porte ali existente.

Ao chegarmos à estação de tratamento da Sanesul, o que já era incomodo, tornouse insuportável com um odor desagradável, observou-se um total descaso com o meio ambiente naquele local.

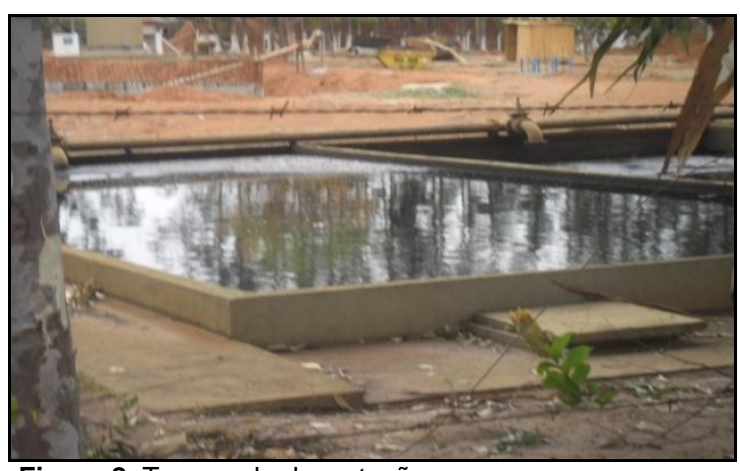

Figura 8: Tanque de decantação.

Fonte: DURÃES, M.S., 2011.

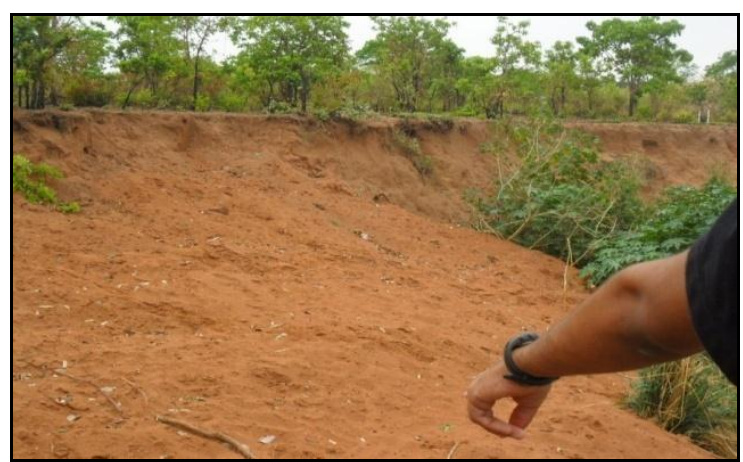

Figura 10: Assoreamento em processo acelerado. Fonte: SANTOS, J.F., 2011.

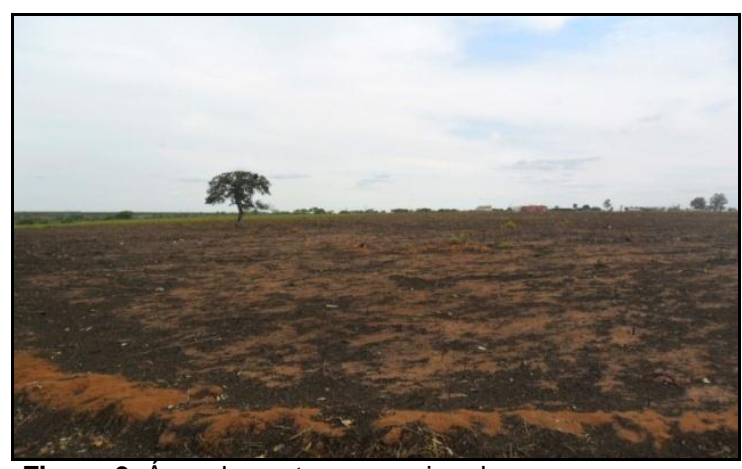

Figura 9: Área de pastagem queimada. Fonte: SANTOS, J.S., 2011.

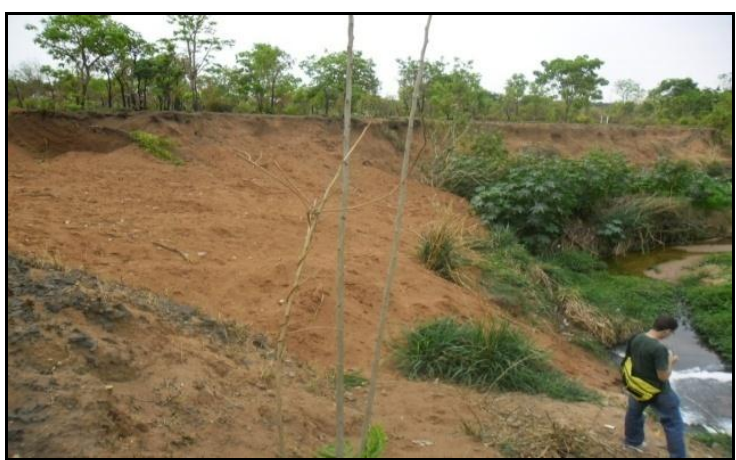

Figura 11: Deslizamento de solo em direção ao córrego. Fonte: SANTOS, J.S., 2011. 


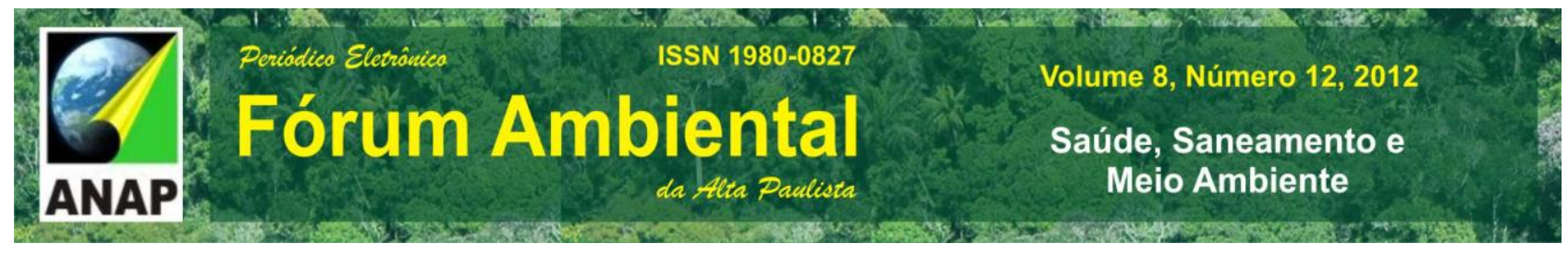

Nas proximidades da estação de tratamento, outra falta de competência ou conhecimento, observamos quando encontramos uma antiga erosão próxima ao córrego que foi soterrada de modo equivocado podendo causar ainda mais o assoreamento do referido córrego. A terra solta tende a escorrer e assorear o córrego, já que se pode dizer que não existe vegetação neste local (Figura 10 e 11).

A obra de ampliação da estação de tratamento, que na verdade não ocorre tratamento nenhum, somente a decantação da matéria orgânica, onde a água lançada no que resta do córrego é mais escura que a água que já era contaminada desde a lagoa.

Os processos erosivos têm papel de protagonista na disseminação do córrego, pois a cada dia o leito do córrego passa a ser maior. Sem contar com as obras impactantes da Sanesul que persistem em desviar o canal do córrego que é meandrante uma vez que a cidade tem problemas com a declividade, contudo estas obras só resultam em gasto do dinheiro público.

Os canais meândricos são aqueles em que os rios descrevem curvas sinuosas, largas, harmoniosas e semelhantes entre si, através de um trabalho contínuo de escavação na margem côncava (ponto de maior velocidade da corrente) e de deposição na margem convexa (ponto de menor velocidade). Deve-se notar que a deposição dos detritos da carga do leito se faz no mesmo lado da margem em que eles foram arrancados (CHRISTOFOLETTI, 2009, p. 88).

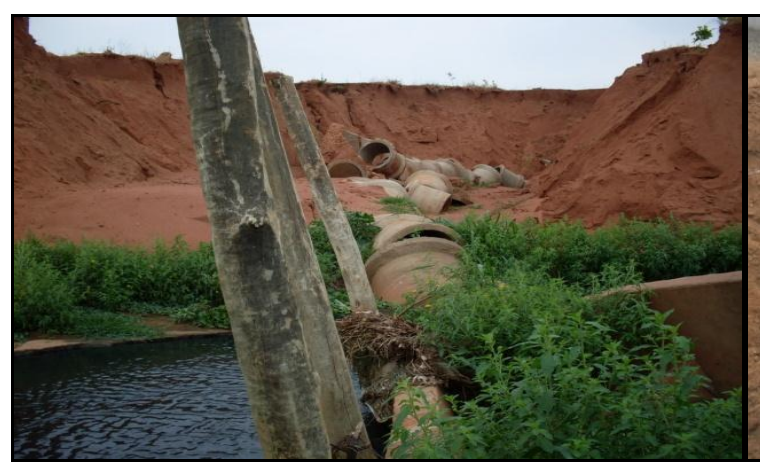

Figura 12: Tentativa de canalizar o restante do córrego. Fonte: SANTOS, J.S., 2011.

Figura 13: Ampliação equivocada da estação.

Fonte: SILVA, J.A.L., 2011.

\section{CONSIDERAÇÕES FINAIS}

Através do trabalho de campo foi constatada evidentemente a importância de sair da sala de aula com os conceitos e relacioná-los com o empírico visto nos bairros e 
posteriormente no córrego da onça. Também vale salientar que a falta de cuidados com o meio ambiente interfere diretamente na qualidade de vida da população.

Contudo foi visto a total falta de planejamento da prefeitura municipal em relação à aprovação de determinadas obras de engenharia no córrego, mostrando o descaso que existe com os bairros periféricos, onde o esquecimento das questões sociais provoca todo tipo de segregação evidenciada nos referidos bairros.

\section{REFERÊNCIAS}

CHRISTOFOLETTI, A. Geomorfologia. São Paulo: Editora Blucher, 2009.

HAESBAERT, R. Da desterritorialização à multiterritorialidade. Anais do X Encontro de Geógrafos da América Latina. São Paulo, 2005.

SANTOS, M. A natureza do espaço: técnica e tempo. razão e emoção. São Paulo: Edusp, 2009.

Espaço e método. São Paulo: Nobel, 1992. 